AperTO - Archivio Istituzionale Open Access dell'Università di Torino

\title{
Do glucocorticoids induce addiction in humans?
}

\section{This is the author's manuscript}

Original Citation:

Availability:

This version is available http://hdl.handle.net/2318/1636192

since 2019-04-25T23:29:28Z

Published version:

DOI:10.1007/s40618-017-0656-4

Terms of use:

Open Access

Anyone can freely access the full text of works made available as "Open Access". Works made available under a Creative Commons license can be used according to the terms and conditions of said license. Use of all other works requires consent of the right holder (author or publisher) if not exempted from copyright protection by the applicable law. 
Do glucocorticoids induce addiction in humans?

\section{R. Giordano1,2 · F. Guaraldi2 - M. Mazzoli2 • E. Ghigo2}

R. Giordano roberta.giordano@unito.it

1 Department of Biological and Clinical Sciences, University of Turin, Turin, Italy 2 Division of Endocrinology, Diabetes and Metabolism, Department of Medical Sciences, University of Turin, Corso Dogliotti, 14, 10126 Turin, Italy

\section{Keywords Glucocorticoids $\cdot$ Humans $\cdot$ HPA axis recovery $\cdot$ Psychiatric disorders $\cdot$ Addiction}

Glucocorticoids (GCs) are among the most widely used drugs in the world for the proven efficacy in the treatment of a variety of diseases, mainly chronic respiratory, autoimmune and neoplastic disorders [1]. It is estimated that approximately $1 \%$ of the Western world receives prolonged therapy with synthetic GCs, resulting in a supraphysiological exposure [1]. During GC treatment, patients often present with signs and symptoms of hypercortisolism, i.e., impaired glucose and calcium metabolism, hypertension and psychiatric disorders [2]. At the same time, GC withdrawal can induce psychiatric complaints [2] and physical discomfort (e.g., fatigue, lethargy, dizziness and weakness), suggestive for hypocortisolism ('tertiary hypoadrenalism') [3]. About 2-60\% of adults treated with high GC doses develops psychiatric disturbances, ranging from mood alterations to overt psychosis [2, 4-6], usually recovering within 6 weeks after treatment cessation. The risk largely depends on GC dose (high risk of psychosis in patients receiving $\geq 40 \mathrm{mg} / \mathrm{day}$ of prednisone, or equivalents), rapidity of dose changes and, to a lesser extent, advanced age, intercurrent illnesses, female gender and history of psychiatric disorders [3-6]. Psychosis could depend in part to the anticholinergic properties of GCs, accelerating the production of tyrosine hydroxylase and dopamine $\beta$-hydroxylase - which, in turn, leads to an increased serum catecholamine activity and altered serotonergic and somatostatin activity — and the GABA agonism, exerted through the binding to GABA-A-receptor complex [2, 4-6]. Prevention strategies include the administration of the lowest possible GC dose, caution in treating patients at risk of psychiatric complications and avoidance of other drugs that increase circulating GC levels [5,6]. A possible cause of GC-induced psychopathology is the suppression of GC secretion in physiological conditions, which follows a circadian rhythm, and in response to stress, since continuous exposure to synthetic GCs may cause desensitization and reduced responsiveness of the glucorticoid (GR) and mineralcorticoid receptor (MR)-dependent neuronal networks [7]. When synthetic GCs (like dexamethasone, prednisone and related steroids that have limited brain penetration) are used, the depletion of endogenous GC levels may cause a hypocortisolemic state in the brain-particularly lack of MR and episodic GR activation-with a consequent severe MR/GR imbalance [7]. At this purpose, replacement therapy with modified released GCs that better mimic the circadian pattern may be beneficial in restoring the MR/GR balance [7]. Patients treated with $\geq 20 \mathrm{mg} / \mathrm{day}$ of prednisone - or equivalent doses of other steroids - for $\geq 5$ days are at risk of hypoadrenalism, while this condition is uncommon for shorter treatments, independently from the dose [3, 7]. Moreover, the risk seems higher in case of oral as compared to inhaled or topical administration [3]. However, because of the considerable variability in individual response to exogenous GCs, treatment dose and duration are not considered good predictors of the degree of HPA axis suppression [3]. Timing of HPA axis recovery after GC discontinuation is also largely variable. According to some studies, the higher is the GC dose, the longer is the time required for HPA recovery, independently from treatment duration; on the contrary, other studies suggested no correlations between the dose and duration of GC exposure and time of recovery [3, 7, 8]. In this context, it seems appropriate to consider the lesson learned from endogenous hypercortisolism. Indeed, in patients surgically treated for endogenous Cushing's syndrome, signs and symptoms of hypocortisolism can persist even longer than one year after disease remission despite GC replacement therapy [8]. It is a paradigm of neuroendocrinology that the recovery of the HPA axis is a matter of time, although it generally occurs within months, rarely years. During this period, 
patients report signs and symptoms suggestive for GC deficiency, the so-called GCs withdrawal syndrome, even when the endogenous HPA axis function is apparently normal at biochemical evaluation [8]. A recent study demonstrated that HPA axis recovery was dependent on the etiology of Cushing's syndrome, being shorter in ectopic ACTHdependent forms, intermediate in ACTHdependent pituitary disease and longer in adrenal Cushing's syndrome [9]. The mechanisms underlying GCs withdrawal syndrome and HPA axis recovery are poorly understood, although a combination of physical and psychological dependence has been postulated, associated with secretory and functional alterations of various neurohormones-i.e., CRH, vasopressin and proopiomelanocortin peptide (POMC) - and central neurotransmitters - i.e., dopamine, noradrenaline and serotonin [8]. Hypothalamic production of CRH seems the timelimiting step for the HPA axis recovery. CRH levels in the cerebrospinal fluid of patients with Cushing's disease are markedly decreased, suggesting a restraint in its brain production [10]. Moreover, an intact CRH system appears necessary for the adequate mesolimbic dopaminergic function. Therefore, $\mathrm{CRH}$ hyposecretion during GC withdrawal may contribute to anxiety and depression via inadequate stimulation of the dopaminergic neurons terminating in the nucleus accumbens $[8,10]$. However, chronic postoperative CRH stimulation of the pituitary cannot shorten the period of GC replacement therapy [10], therefore suggesting the influence of other neurotransmitters pathways in HPA axis recovery. Actually, vasopressin production and release in hypothalamic neurons are reduced in chronic hypercortisolism [10]. Since vasopressin is involved in memory process, mood and concentration, it may be postulated that behavioral and mood changes occurring during both hypercortisolism and GC withdrawal may also reflect the effects of chronic altered vasopressin direct or CRH-mediated action on central neurons $[8,10]$. On the other hand, symptoms of GC dependence and withdrawal could mimic those associated with opiates, since POMC derivative peptide secretion is also altered during hypercortisolism, and the recovery is gradual and parallel to HPA axis function [8, 10]. The central noradrenergic and dopaminergic systems may also contribute to the occurrence of mood disorders associated with both Cushing's syndrome and GCs withdrawal syndrome [8, 10], since acute stress-induced HPA activation and dopamine release in the mesolimbic system promote behavioral activation toward appropriate stimulus response, while prolonged stress exposure inhibits the mesolimbic dopaminergic system, with failure of coping, and subsequent depressive manifestations [5, 10]. Moreover, panic behavior, anxiety and increased sympathoadrenal activity have been reported in the postoperative period in patients lacking of proper replacement treatment after successfully treatment for Cushing's syndrome, subsiding after functional recovery of CRH and noradrenergic neurons [10]. The interplay between the central noradrenergic system and GCs in the pathogenesis of mood changes has still to be fully clarified, since both increased and decreased noradrenergic activity has been described in depression and in association with response to antidepressants $[5,6]$. Based on these premises, and the difficulties commonly experienced by physicians when there is a need of reducing/ stopping GCs after prolonged treatments, due to the poor patient tolerance to the physical/psychophysical discomfort subsequent to the transient secondary hypocortisolism, we hypothesize some kind of GC 'addiction.' In other words, we consider patient's discomfort as a collection of signs and symptoms of GC abstinence. Under a clinical point of view, this hypothesis has two important consequences. First of all, the clinical impact of GC withdrawal has not to be underestimated. Second, its prevention and management represent a very challenging issue, since no valid treatment option can be offered in order to accelerate the recovery of HPA function. Indeed, ACTH administration would reexpose the patient to supraphysiological GC levels, so to persistent inhibition of the HPA axis, thus delaying, but not avoiding, the onset of GC withdrawal manifestations. The administration of neuroactive drugs, impinging on neurotransmitters pathways, could theoretically be able to reactivate the CRH/AVP hypothalamic neurons inhibited by the prolonged exposure to synthetic GCs although this hypothesis remains to be demonstrated. On the other hand, based on the hypothesis that a more physiological replacement helps the restoration of the endogenous neuroendocrine mechanisms regulating the HPA axis function, modified released hydrocortisone appears the most 
suitable approach, among currently approved drugs for hypoadrenalism, to prevent signs and symptoms induced by deprivation of synthetic GCs, although clinical trials are mandatory before this treatment could be recommended.

Compliance with ethical standards

Conflict of interest The authors declare that the content of the submitted manuscript (in part or in full) has not been previously published, and is not under consideration for publication elsewhere. Authors also declare they have no conflict of interest that could prejudge the interpretation of the results presented in the manuscript, and that no financial support was received in conjunction with the generation of this submission. Ethical approval This article does not contain any studies with human participants or animals performed by any of the authors.

Informed consent For this type of study formal consent is not required.

\section{References}

1. van Staa TP, Leufkens HG, Abenhaim L, Begaud B, Zhang B, Cooper C (2000) Use of oral corticosteroids in the United Kingdom. QJM 93:105-111

2. Judd LL, Schettler PJ, Brown ES, Wolkowitz OM, Sternberg EM, Bender BG, Bulloch K, Cidlowski JA, de Kloet ER, Fardet L, Joëls M, Leung DY, McEwen BS, Roozendaal B, Van Rossum EF, Ahn J, Brown DW, Plitt A, Singh G (2014) Adverse consequences of glucocorticoid medication: psychological, cognitive, and behavioral effects. Am J Psychiatry 171:1045-1051. doi:10.1176/appi.ajp.2014.13091264

3. Broersen LH, Pereira AM, Jørgensen JO, Dekkers OM (2015) Adrenal insufficiency in corticosteroids use: systematic review and meta-analysis. J Clin Endocrinol Metab 100:2171-2180. doi:10.1210/jc.2015-1218

4. Hall R, Popkin M, Stickney S, Gardner ER (1979) Presentation of the steroid psychoses. J Nerv Ment Dis 167:229-236

5. Warrington TP, Bostwick JM (2006) Psychiatric effects of corticosteroids. Mayo Clin Proc 81:1361-1367

6. Dubovsky AN, Arvikar S, Stern TA, Axelrod L (2012) The neuropsychiatric complications of glucocorticoid use: steroid psychosis revisited. Psychosomatics 53:103-115. doi:10.1016/j. psym.2011.12.007

7. Oster H, Challet E, Ott V, Arvat E, de Kloet ER, Dijk DJ, Lightman S, Vgontzas A, Van Cauter E (2016) The functional and clinical significance of the 24-h rhythm of circulating glucocorticoids. Endocr Rev. doi:10.1210/er.2015-1080

8. Hochberg Z, Pacak K, Chrousos GP (2003) Endocrine withdrawal syndromes. Endocr Rev 24:523-538

9. Berr CM, Di Dalmazi G, Osswald A, Ritzel K, Bidlingmaier M, Geyer LL, Treitl M, Hallfeldt K, Rachinger W, Reisch N, Blaser R, Schopohl J, Beuschlein F, Reincke M (2015) Time to recovery of adrenal function after curative surgery for Cushing' syndrome depends on etiology. J Clin Endocrinol Metab 100:1300-1308. doi:10.1210/jc.2014-3632

10. Dorn LD, Burgess ES, Friedman TC, Dubbert B, Gold PW, Chrousos GP (1997) The longitudinal course of psychopathology in Cushing's syndrome after correction of hypercortisolism. J Clin Endocrinol Metab 82:912-919 